\title{
A INFLUÊNCIA DA PRECIPITAÇÃO E DA TEMPERATURA SOBRE AS OCORRÊNCIAS DE FEBRE CHIKUNGUNYA NO MUNICÍPIO DE BELÉM DO PARÁ, BRASIL
}

THE INFLUENCE OF CLIMATIC VARIABLES OF PRECIPITATION AND TEMPERATURE ON THE OCCURRENCES OF CHIKUNGUNYA FEVER IN BELÉM, PARÁ, BRAZIL

\section{Jaqueline Portal da Silva (10)}

Doutoranda do Programa de Pós Graduação Ciências Ambientais, UFPA/MPEG/EMBRAPA e docente da Universidade Federal do Oeste do Pará, UFOPA -

Santarém (PA), Brasil.

\section{Márcia Aparecida} da Silva Pimentel (B)

Docente na Universidade Federal do Pará (UFPA), Programa de Pós-Graduação em Ciências Ambientais (PPGCA) - Belém (PA), Brasil.

\section{Mário Augusto \\ Gonçalves Jardim (1)}

Pesquisador do Ministério da Ciência, Tecnologia, Inovações e Comunicações, Museu Paraense Emílio Goeldi (MPEG) - Belém (PA), Brasil.

\section{Endereço para correspondência:} Jaqueline Portal da Silva - Instituto de Ciência e Tecnologia das Águas Rua Vera Paz, s/n. - Salé - CEP 68040-470 - Santarém (PA), Brasil E-mail: jaqueline.silva@ufopa.edu.br

Recebido em: 03/07/2019

Aceito em: 08/11/2019

\section{RESUMO}

O objetivo desta pesquisa foi avaliar a influência das variáveis climáticas temperatura do ar e precipitação pluviométrica sobre as ocorrências de febre chikungunya (CHIKF). Conduziu-se o estudo no período de 2016 a 2018, com área de aplicação no município de Belém (PA). Analisaram-se as variáveis com base em estatísticas descritivas, das quais foram determinados média, desvio padrão, coeficiente de variação, mediana, mínimo e máximo. As normalidades das variáveis foram definidas pelo uso de testes de correlação paramétricos ou não paramétricos. Procedeu-se à análise de regressão linear múltipla para as variáveis que apresentaram significância estatística. A sazonalidade foi confirmada com registros de CHIKF mais altos no primeiro semestre do ano, quando são registradas as maiores incidências de chuvas e as temperaturas mais amenas da região. A correlação de Pearson identificou associação entre as ocorrências de CHIKF e as variáveis de temperatura e precipitação em 2016, que apresentaram, respectivamente, associação positiva e fraca e associação negativa e fraca. Em Belém, as características climáticas locais favorecem a manutenção da CHIKF, entretanto, no estudo das arboviroses, devem ser considerados outros elementos também, como os fatores socioambientais.

Palavras-chave: arbovirose; doenças tropicais negligenciadas; epidemiologia.

\section{ABSTRACT}

The objective of this research was to evaluate the influence of climatic variables of air temperature and rainfall on the occurrence of Chikungunya fever (CHIKF). The study was conducted from 2016 to 2018, with application area in the municipality of Belém (PA). The variables were analyzed based on descriptive statistics from which mean, standard deviation, coefficient of variation, median, minimum and maximum were determined. Normality tests were performed to define by using the parametric or nonparametric correlation tests. For the variables that presented statistical significance, the multiple linear regression analysis was performed. Seasonality was confirmed with higher CHIKF records in the first half of the year, when the highest rainfall and mildest temperatures in the region are recorded. Pearson's correlation identified an association between CHIKF occurrences and temperature and precipitation variables in 2016, which presented respectively positive and weak association and negative and weak association. In Belém, local climatic characteristics favor the maintenance of Chikungunya fever, however in the study of arboviruses other factors such as social and environmental factors should be considered.

Keywords: arbovirus; neglected tropical diseases; epidemiology. 


\section{INTRODUÇÃO}

A febre chikungunya (CHIKF) é uma doença viral com primeira epidemia documentada na Tanzânia, no continente africano, em 1952, com focos subsequentes identificados na África e na Ásia nos anos 1950 e 60 (JANSEN et al., 2015; PANDEY et al., 2015; WIMALASIRI-YAPA et al., 2019). Em 2004, um surto de CHIKF originado na costa do Quênia se expandiu, atingindo em 2005 ilhas do Oceano Índico. No ano de 2006, epidemias da doença ocorreram na Índia e em alguns países do sudeste asiático. Em 2007, casos autóctones da arbovirose foram reportados na Itália, na região de Ravena, e no ano de 2010 o vírus voltou a causar surtos em países como Índia, Indonésia, Myanmar, Tailândia, Ilhas Maldivas e Ilha de Reunião, além do sul da França, que registrou casos autóctones da doença (HONÓRIO et al., 2015; GOULD et al., 2010; HUMPHREY et al., 2017; MAHAJAN; MAHAJAN, 2018; WIMALASIRI-YAPA et al., 2019).

Nas Américas, o primeiro caso autóctone da doença foi registrado na região do Caribe, em dezembro de 2013. No ano seguinte, países da América do Sul, entre os quais Guiana Francesa, Suriname, Paraguai, Colômbia e Venezuela, registraram a circulação do vírus em seus territórios (DONALISIO; FREITAS, 2015; HALSTEAD, 2015; NAVECA et al., 2019).

No Brasil, o primeiro caso autóctone da doença ocorreu em 2014, na cidade do Oiapoque, no Amapá, estado que faz fronteira com a Guiana Francesa, e no município de Feira de Santana, na Bahia (DONALISIO; FREITAS, 2015; HONÓRIO et al., 2015; SILVA et al., 2018b).

Quanto aos sinais e sintomas, a CHIKF tem apresentação clínica que se assemelha à da dengue, ou seja, febre de início agudo, cefaleia, náuseas, fadiga e dores musculares. Entretanto, a principal manifestação clínica que a difere da dengue são as fortes dores nas articulações, tendo como consequência a redução da produtividade e da qualidade de vida (PANDEY et al., 2015; SAM et al., 2015; MAHAJAN; MAHAJAN, 2018).

Há duas espécies principais de mosquitos do gênero Aedes com capacidade de transmitir a CHIKF: o Aedes aegypti e o Aedes albopictus, ambas espécies invasoras e cosmopolitas que se desenvolvem principalmente em áreas tropicais e subtropicais, como a África, as Américas Central e do Sul, o Caribe, parte da Austrália,
Ásia e algumas ilhas no Pacífico e Índico, por causa das condições climáticas e ambientais que favorecem sua proliferação (HONÓRIO et al., 2015; PATTERSON et al., 2016; REINHOLD et al., 2018).

No Brasil, o $A$. aegypti é o principal vetor de arbovírus como a dengue, febre amarela, zika e chikungunya. De comportamento antropofílico, esse mosquito evoluiu para viver todo o seu ciclo de vida, de larvas a adultos, em estreita proximidade com seus hospedeiros humanos (HONÓRIO et al., 2015; PATTERSON et al., 2016; REINHOLD et al., 2018). Nas décadas de 1950 e 60, o mosquito Aedes foi intensamente combatido no país, sobretudo enquanto vetor da febre amarela, um problema de saúde pública nas Américas, quando após diversas campanhas se acreditou que ele havia efetivamente sido erradicado do território nacional e de quase todos os países latino-americanos, a exceção de Suriname, Venezuela, Cuba, Jamaica, Haiti, República Dominicana e Colômbia (AZEVEDO et al., 2011). Porém, em razão das mudanças ambientais e sociais, como o intenso processo de urbanização ocorrido no país, além de falhas nas ações de controle da vigilância epidemiológica, deu-se em 1967 sua reinfestação no município de Belém do Pará, e em meados de 1970 no Rio de Janeiro. Atualmente, o A. aegypti pode ser encontrado em todas as unidades federativas do território nacional (AZEVEDO et al., 2011; COSTA et al., 2011).

Em seu ciclo de desenvolvimento, o A. aegypti passa pelas fases de ovo, larva, pupa e mosquito adulto. Seus ovos são resistentes à dessecação, e em contato com a água, após a eclosão, seu desenvolvimento até a forma adulta pode levar um período de até dez dias. A duração da fase larval não passa de cinco dias, enquanto a fase da pupa dura dois ou três dias. Somente as fêmeas picam o homem, pois necessitam das proteínas presentes no sangue para maturar seus ovos, podendo realizar quatro ou cinco ciclos reprodutivos e viver na natureza em média de 30 a 35 dias (ALMEIDA; SILVA, 2017; REINHOLD et al., 2018; FIOCRUZ, 2019).

$\mathrm{O}$ vírus chikungunya (CHIKV) é transmitido de humano para humano pela picada do mosquito fêmea infectado, e após um período de incubação que varia de um a doze dias (geralmente de três a sete dias), ocorre a viremia da doença e os sintomas desenvolvem-se. Ao entrar no mosquito, por meio das picadas, o vírus 
também requer um período de incubação que pode variar de seis a quinze dias, antes de poder ser transmitido a outra pessoa, e para que a transmissão ocorra, o mosquito deverá picar a pessoa infectada durante a fase de viremia da doença (RAMADONA et al., 2016; MAHAJAN; MAHAJAN, 2018).

Na transmissão das doenças arbovirais, as variáveis climáticas são conhecidas como fatores que favorecem a dinâmica do mosquito vetor, uma vez que a elevação da temperatura reduz o tempo de desenvolvimento das larvas, aumentando a população de vetores adultos; diminui o período de incubação extrínseca, isto é, o tempo para que o vírus alcance a glândula salivar do mosquito, possibilitando, assim, maiores proporções de mosquitos infecciosos; e influencia na frequência com que as fêmeas adultas do mosquito se alimentam, o que aumenta a intensidade da transmissão (CORRÊA et al., 2016). Por sua vez, a pluviosidade contribui para o crescimento do número de criadouros disponíveis, propiciando ambiente favorável à procriação do mosquito (VIANA; IGNOTTI, 2013).

Em razão da recente inserção da CHIKF no Brasil, ainda são poucos os estudos voltados à sua compreensão. Honório et al. (2015), Donalisio e Freitas (2015) e Silva et al. (2018b) em suas pesquisas descrevem as principais características da CHIKF e sua importância no contexto da saúde pública. Costa et al. (2018), Rodrigues et al. (2018a; 2018b), Silva et al. (2018a) e Tauro et al. (2019) desenvolveram estudos epidemiológicos relacionados às variáveis climáticas, socioeconômicas e ambientais, enquanto Naveca et al. (2019) investigaram a diversidade genética de cepas circundantes da CHIKF na cidade de Boa Vista, no estado de Roraima, na Amazônia brasileira.

A localização geográfica do Brasil, situado na região entre $5^{\circ}$ Norte e $10^{\circ} \mathrm{Sul}$, entre os trópicos de Capricórnio e de Câncer, favorece a elevada incidência de radiação solar que o país recebe, enquanto a zona de convergência intertropical (ZCIT) sobre o Atlântico equatorial é um dos principais indutores das chuvas sobre a re- gião amazônica (MOREIRA et al., 2019; FRANCO et al., 2019). Ainda segundo ambos os autores, fatores como a topografia local, a cobertura vegetal, o ciclo hidrológico e a influência das correntes oceânicas nas regiões costeiras concorrem para a modulação do clima de determinada região.

Inserido nesse ambiente, o município de Belém do Pará, na Amazônia brasileira, caracteriza-se por temperaturas sempre elevadas, forte convecção e alta umidade do ar, favorecendo a formação de nuvens convectivas do tipo cúmulo-nimbo, que dão origem à grande incidência de precipitações na forma de pancadas de chuva, principalmente à tarde. Destaca-se ainda que o município, como todo grande aglomerado urbano, cria um clima com dinâmicas próprias, gerando anomalias na temperatura do ar, na umidade e na circulação local (BASTOS et al., 2002). Corrêa et al. (2016) afirmam que as áreas tropicais e subtropicais entre os paralelos (latitudes) $35^{\circ}$ Norte e $35^{\circ}$ Sul constituem regiões que possuem o limite climático ótimo para o desenvolvimento de mosquitos vetores como o Aedes.

O primeiro caso autóctone de CHIKF em Belém foi confirmado em 2015, e, em função da sua recente introdução no município, são insipientes os estudos que abordam essa temática na região. Nesse sentido, compreender a inserção de Belém conforme uma dinâmica climática mais abrangente, em termos global e regional, e sua interação com seus fenômenos climáticos urbanos é um aspecto que deve ser considerado no contexto de um estudo epidemiológico, especialmente nas pesquisas relacionadas às arboviroses, uma vez que o aquecimento global associado a condições ambientais locais, naturais e/ou antrópicas poderá potencializar a expansão das doenças arbovirais transmitidas por mosquitos vetores, que passaram a constituir preocupação a nível global.

Com base nessas considerações, o presente estudo teve o objetivo de analisar a influência das condições climáticas de precipitação pluviométrica e temperatura do ar nas ocorrências de CHIKF no município de Belém.

\section{MATERIAL E MÉTODOS}

\section{Área de estudo}

O município de Belém constitui-se como um dos maiores municípios da Amazônia em termos populacionais, com população estimada de 1.393.399 habitantes, dos quais $99 \%$ residem em sua porção urbana, conforme os 
dados censitários do Instituto Brasileiro de Geografia e Estatística (IBGE, 2010).

Situa-se nas coordenadas geográficas de $01^{\circ} 26^{\prime}$ de latitude ao sul e $48^{\circ} 26^{\prime}$ de longitude a oeste de Greenwich, às margens da Baía do Guajará e do Rio Guamá, distante a 120 quilômetros do Oceano Atlântico, no estuário do Rio Pará (MOREIRA et al., 2019) (Figura 1).

As altas temperaturas do município justificam-se por sua localização um pouco abaixo da linha do Equador, na zona climática Af (segundo a classificação de Köppen). O clima é do tipo tropical úmido, de floresta equatorial, caracterizado por sua grande precipitação anual acumulada, que pode variar de 2.300 a $3 \mathrm{mil} \mathrm{mm}$ em determinadas áreas.

Em Belém, há dois períodos climáticos distintos: um mais chuvoso (de dezembro a maio) e outro menos chuvoso (de junho a novembro) (MOREIRA et al., 2019). A temperatura média de $26,4^{\circ}$ e a umidade relativa do ar de $84 \%$ favorecem a formação de nuvens convectivas (COSTA; BLANCO, 2018).

A topografia é pouco variável e plana na área urbana e há grandes áreas que estão abaixo do nível do mar e que sofrem influência das marés altas, dificultando o escoamento das águas pluviais (MOREIRA et al., 2019).

A área continental do município é composta de 13 bacias hidrográficas, e sua área insular é formada por 39 ilhas, que correspondem a $65,64 \%$ da sua área total. Todo o sistema hidrográfico da região sofre a influência das marés do Oceano Atlântico, e as oscilações dos níveis das águas, decorrentes das variações sazonais, elevam o nível d'água dos inúmeros canais que cortam a cidade, ocasionando inundações periódicas. Essa situação agrava-se quando as marés altas coincidem com o período chuvoso da região (FENZL et al., 2010).

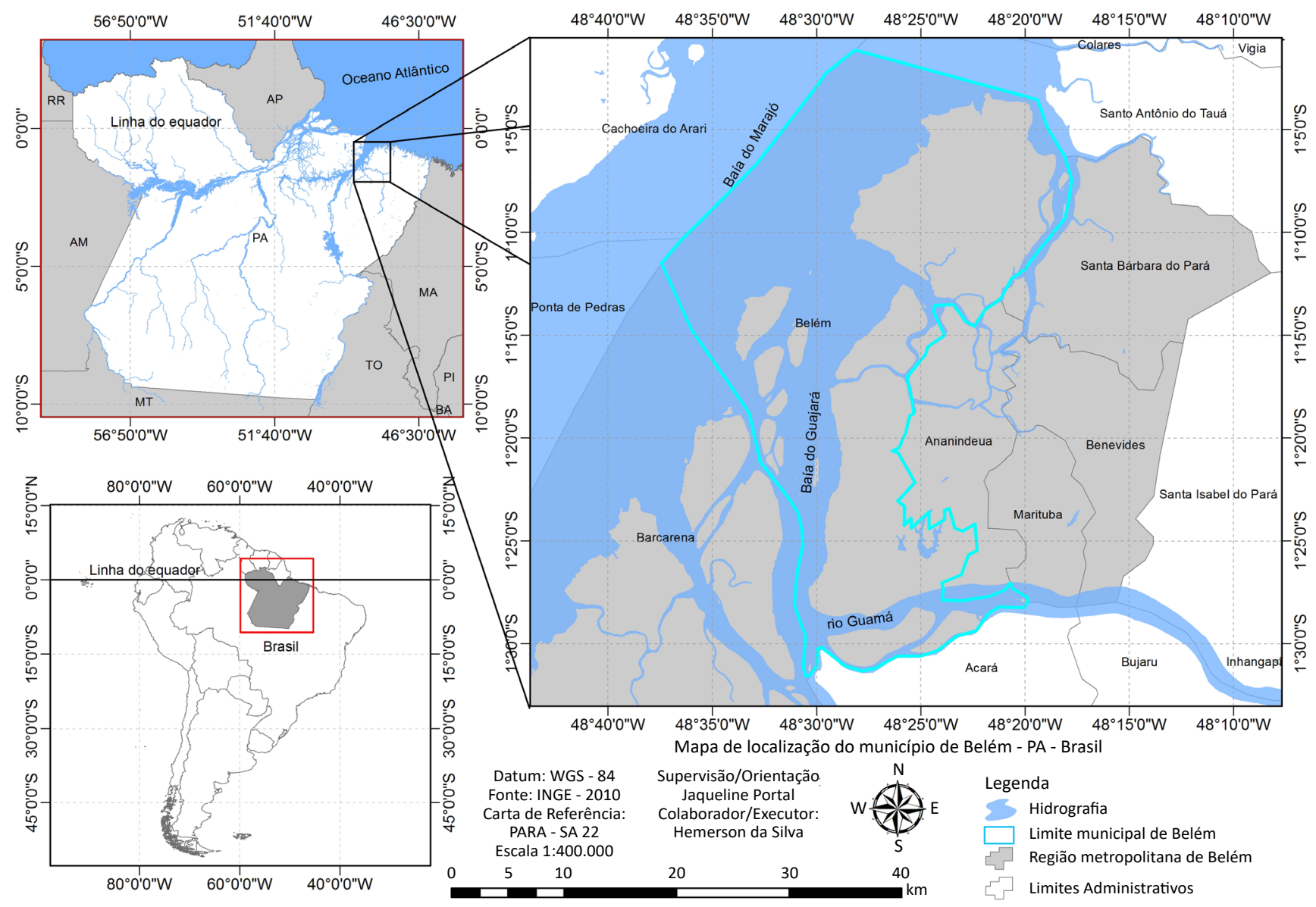

Figura 1 - Mapa de localização de Belém do Pará, Brasil. 


\section{Procedimentos metodológicos}

Os dados semanais de precipitação pluviométrica $(\mathrm{mm})$ e temperatura do $\operatorname{ar}\left({ }^{\circ} \mathrm{C}\right)$ foram disponibilizados pelo Instituto Nacional de Meteorologia (INMET), da Estação Meteorológica de Belém, referentes aos anos Por sua vez, os dados de CHIKF foram disponibilizados pelo Departamento de Controle de Endemias da Secretaria de Saúde Pública do Pará (SESPA), por meio do banco de dados das notificações de CHIKF do Sistema de Informação de Agravos de Notificação (SINAN).

Analisaram-se os dados climáticos e de CHIKF com base em estatísticas descritivas, das quais foram determinados média, desvio padrão, coeficiente de variação, mediana, mínimo e máximo.

Foram realizados testes de normalidade de Kolmogorov-Smirnov, e para as variáveis que apresentaram $\mathrm{p}<$ 0.05 , optou-se pela logaritmização como medida para normalizar e homogeneizar a distribuição das variáveis, definindo-as, posteriormente, pelo uso de testes paramétricos de correlação linear de Pearson ( $r$ ) ou testes não paramétricos de correlação de Spearman ( $\rho)$, que são medidas de associação entre variáveis numéricas e variam de -1 a 1 . Quanto mais próximo de -1 ou 1 , a correlação é dita perfeita.

Para as variáveis que apresentaram significância estatística, procedeu-se à aplicação da análise de regressão linear múltipla, cujo princípio consiste em modelar uma variável dependente (y), neste estudo representada pelas ocorrências de CHIKF, por meio da combinação linear de variáveis explicativas (x) ou independentes, representadas pelas variáveis climáticas.
Entretanto, antes de aplicar o modelo de regressão, foi preciso testar a significância das variáveis, pelo teste de significância global, ou teste $F$, que responde à seguinte pergunta: "o modelo é útil para prever a ocorrência de CHIKF com base nas variáveis de precipitação e temperatura?".

Escolhido o modelo de regressão, devem-se estimar os coeficientes da equação da reta, $\hat{\beta}_{0}$ e $\hat{\beta}_{1}$. Isso pode ser feito mediante a aplicação do método dos mínimos quadrados, sendo a estimativa dada pela Equação 1:

$\hat{y}_{i}=\hat{\beta}_{0}+\hat{\beta}_{1} x_{i}+\hat{\beta}_{2} x_{i}$

Em que:

$\hat{y}_{i}=$ variável explicada (dependente), que no nosso estudo é a CHIKF;

$\hat{\beta}_{0}=$ constante, que representa a intercepção da reta com o eixo vertical;

$\hat{\beta}_{1}$ e $\hat{\beta}_{2}=$ constantes que representam o declive (coeficiente angular) da reta;

$x_{i}=a$ variável explicativa (independente), que no presente trabalho são as variáveis climáticas.

Esta pesquisa foi protocolada na Plataforma Brasil, avaliada e aprovada pelo Comitê de Ética em Pesquisa do Instituto de Ciências Biológicas da Universidade Federal do Pará (UFPA), conforme Certificado de Apresentação para Apreciação Ética (CAAE), protocolo 91680318.6.0000.0018.

\section{RESULTADOS}

\section{Variáveis climáticas e epidemiológicas}

Na Tabela 1, são elencados os dados semanais de temperatura do ar, precipitação pluviométrica e ocorrências de CHIKF, para os anos de 2016, 2017 e 2018, do município de Belém. A Tabela 2 contém estatísticas descritivas semestrais das variáveis climáticas de temperatura, precipitação e ocorrências de CHIKF.

No triênio, a temperatura apresentou comportamento sazonal com maiores índices registrados no segundo semestre.
Os maiores índices de precipitação foram registrados no primeiro semestre de 2016 e 2017, e em 2018 o maior índice de precipitação foi identificado no segundo semestre.

As maiores ocorrências de CHIKF deram-se no primeiro semestre, com exceção do ano de 2016, que identificou maiores ocorrências no segundo semestre, possivelmente relacionadas às subnotificações da doença, que somente confirmou o primeiro caso autóctone em 2015. 
Tabela 1 - Dados semanais de precipitação total, temperatura média e ocorrências de febre chikungunya (CHIKF), no período de 2016 a 2018, para Belém (PA).

\begin{tabular}{|c|c|c|c|c|c|c|c|c|c|}
\hline \multirow[b]{2}{*}{ Semana } & \multicolumn{3}{|c|}{2016} & \multicolumn{3}{|c|}{2017} & \multicolumn{3}{|c|}{2018} \\
\hline & CHIKF & $\begin{array}{l}\text { T. ar } \\
\left({ }^{\circ} \mathrm{C}\right)\end{array}$ & $\begin{array}{l}\text { Precipitação } \\
\text { (mm) }\end{array}$ & CHIKF & $\begin{array}{l}\text { T. ar } \\
\left({ }^{\circ} \mathrm{C}\right)\end{array}$ & $\begin{array}{l}\text { Precipitação } \\
\text { (mm) }\end{array}$ & CHIKF & $\begin{array}{l}\text { T. ar } \\
\left({ }^{\circ} \mathrm{C}\right)\end{array}$ & $\begin{array}{l}\text { Precipitação } \\
\text { (mm) }\end{array}$ \\
\hline 1 & 0 & 27,60 & 38,30 & 1 & 26,53 & 134,3 & 13 & 26,80 & 187,48 \\
\hline 2 & 0 & 27,45 & 67,00 & 7 & 26,17 & 80,7 & 16 & 26,07 & 182,64 \\
\hline 3 & 1 & 27,72 & 135,60 & 15 & 26,32 & 104,4 & 15 & 26,54 & 186,36 \\
\hline 4 & 0 & 27,01 & 8,39 & 11 & 26,30 & 186,7 & 24 & 26,26 & 183,32 \\
\hline 5 & 1 & 25,91 & 97,70 & 7 & 26,74 & 150,1 & 40 & 26,11 & 181,18 \\
\hline 6 & 0 & 27,03 & 152,50 & 12 & 26,33 & 169,1 & 41 & 26,03 & 183,02 \\
\hline 7 & 0 & 26,78 & 112,60 & 9 & 25,96 & 116,4 & 28 & 26,40 & 186,92 \\
\hline 8 & 0 & 27,14 & 146,10 & 20 & 26,31 & 174,3 & 54 & 26,09 & 181,32 \\
\hline 9 & 2 & 27,29 & 152,20 & 5 & 26,05 & 127,8 & 84 & 26,77 & 187,34 \\
\hline 10 & 0 & 27,24 & 184,50 & 27 & 25,78 & 142,2 & 89 & 27,04 & 190 \\
\hline 11 & 0 & 27,09 & 152,20 & 18 & 25,71 & 211,3 & 99 & 27,03 & 189,38 \\
\hline 12 & 0 & 27,22 & 106,40 & 21 & 26,30 & 99,8 & 101 & 26,74 & 185,82 \\
\hline 13 & 1 & 27,32 & 81,90 & 27 & 26,51 & 170,3 & 79 & 26,43 & 185,46 \\
\hline 14 & 0 & 27,40 & 91,20 & 31 & 26,23 & 190,8 & 93 & 26,29 & 183,84 \\
\hline 15 & 0 & 27,50 & 151,40 & 25 & 26,43 & 43,5 & 86 & 26,11 & 182,86 \\
\hline 16 & 0 & 27,78 & 129,30 & 48 & 26,91 & 92 & 101 & 26,77 & 186,98 \\
\hline 17 & 0 & 28,66 & 39,80 & 47 & 26,77 & 109,3 & 98 & 26,44 & 185,76 \\
\hline 18 & 2 & 27,55 & 36,80 & 19 & 26,56 & 158,6 & 57 & 26,48 & 184,3 \\
\hline 19 & 0 & 27,84 & 75,00 & 34 & 27,21 & 103,1 & 110 & 26,34 & 184,52 \\
\hline 20 & 1 & 27,96 & 57,10 & 53 & 27,71 & 25,5 & 103 & 26,82 & 189,14 \\
\hline 21 & 0 & 27,92 & 19,20 & 33 & 27,07 & 15,2 & 114 & 26,63 & 185,08 \\
\hline 22 & 2 & 27,82 & 88,90 & 36 & 27,25 & 40,1 & 89 & 27,15 & 190,96 \\
\hline 23 & 1 & 27,59 & 35,40 & 22 & 27,73 & 15,3 & 129 & 27,24 & 191,54 \\
\hline 24 & 2 & 27,33 & 10,20 & 40 & 27,78 & 34,3 & 93 & 27,43 & 190,78 \\
\hline 25 & 1 & 26,33 & 166,80 & 36 & 27,22 & 59,4 & 101 & 27,07 & 190,72 \\
\hline 26 & 1 & 27,06 & 65,20 & 26 & 27,07 & 49,9 & 146 & 27,67 & 193,88 \\
\hline
\end{tabular}


Tabela 1 - Continuação.

\begin{tabular}{|c|c|c|c|c|c|c|c|c|c|}
\hline \multirow[b]{2}{*}{ Semana } & \multicolumn{3}{|c|}{2016} & \multicolumn{3}{|c|}{2017} & \multicolumn{3}{|c|}{2018} \\
\hline & CHIKF & $\begin{array}{l}\text { T. ar } \\
\left({ }^{\circ} \mathrm{C}\right)\end{array}$ & $\begin{array}{l}\text { Precipitação } \\
\text { (mm) }\end{array}$ & CHIKF & $\begin{array}{l}\text { T. ar } \\
\left({ }^{\circ} \mathrm{C}\right)\end{array}$ & $\begin{array}{l}\text { Precipitação } \\
\text { (mm) }\end{array}$ & CHIKF & $\begin{array}{l}\text { T. ar } \\
\left({ }^{\circ} \mathrm{C}\right)\end{array}$ & $\begin{array}{l}\text { Precipitação } \\
\text { (mm) }\end{array}$ \\
\hline 27 & 0 & 27,03 & 34,20 & 30 & 27,10 & 16,4 & 87 & 27,07 & 189,2 \\
\hline 28 & 3 & 26,90 & 105,90 & 27 & 27,61 & 7,1 & 78 & 26,84 & 187,52 \\
\hline 29 & 6 & 27,25 & 30,40 & 17 & 27,59 & 0 & 82 & 27,59 & 193,54 \\
\hline 30 & 2 & 27,59 & 0,60 & 19 & 27,36 & 5,1 & 49 & 27,13 & 188,84 \\
\hline 31 & 4 & 27,95 & 4,50 & 22 & 27,84 & 7,2 & 79 & 26,48 & 185,64 \\
\hline 32 & 1 & 27,94 & 23,70 & 11 & 27,37 & 16,3 & 84 & 26,75 & 187,5 \\
\hline 33 & 4 & 28,19 & 26,40 & 8 & 27,68 & 23 & 72 & 26,84 & 187,84 \\
\hline 34 & 0 & 27,53 & 24,10 & 19 & 27,08 & 18,4 & 71 & 26,72 & 187,08 \\
\hline 35 & 5 & 27,99 & 23,70 & 9 & 27,60 & 45,3 & 85 & 27,32 & 191,02 \\
\hline 36 & 4 & 27,11 & 36,60 & 1 & 28,26 & 5,8 & 58 & 27,60 & 194,1 \\
\hline 37 & 13 & 27,92 & 11,80 & 3 & 28,28 & 7,6 & 71 & 27,78 & 194,7 \\
\hline 38 & 25 & 27,86 & 3,60 & 7 & 27,65 & 11,9 & 78 & 27,39 & 190,56 \\
\hline 39 & 16 & 28,22 & 4,40 & 9 & 27,65 & 26,2 & 42 & 27,45 & 192,6 \\
\hline 40 & 15 & 27,87 & 40,90 & 10 & 27,01 & 39,3 & 35 & 27,29 & 191,14 \\
\hline 41 & 4 & 28,23 & 32,00 & 2 & 27,61 & 86,6 & 31 & 27,63 & 193,82 \\
\hline 42 & 11 & 28,05 & 12,10 & 5 & 27,71 & 24,8 & 12 & 27,80 & 194,94 \\
\hline 43 & 8 & 27,63 & 76,70 & 6 & 27,40 & 62 & 5 & 27,84 & 194,68 \\
\hline 44 & 19 & 27,05 & 25,00 & 10 & 27,64 & 16,1 & 1 & 27,76 & 193,74 \\
\hline 45 & 31 & 27,04 & 47,00 & 16 & 27,79 & 34,2 & 3 & 27,73 & 194,58 \\
\hline 46 & 21 & 28,42 & 5,40 & 23 & 27,55 & 38 & 1 & 28,21 & 197,5 \\
\hline 47 & 25 & 28,64 & 0,00 & 23 & 27,84 & 4,8 & 3 & 27,79 & 194,08 \\
\hline 48 & 23 & 27,97 & 87,70 & 13 & 28,47 & 20 & 0 & 26,58 & 185,16 \\
\hline 49 & 7 & 27,81 & 58,70 & 8 & 28,07 & 1,3 & 2 & 26,14 & 182,76 \\
\hline 50 & 16 & 26,77 & 127,30 & 14 & 26,22 & 37,9 & 0 & 25,93 & 180,92 \\
\hline 51 & 3 & 26,51 & 21,90 & 10 & 26,28 & 87 & 0 & 26,06 & 182,08 \\
\hline 52 & 11 & 26,96 & 99,60 & 20 & 26,99 & 117,2 & 0 & 26,20 & 184,14 \\
\hline
\end{tabular}

T. ar: grau Celsius (símbolo: ${ }^{\circ} \mathrm{C}$ ). 
De acordo com o banco de dados do Sinan e Sespa, o primeiro caso de CHIKF confirmado na capital do estado ocorreu no ano de 2015 (um caso). Nesse mesmo ano também foi confirmada a ocorrência da doença no município de São Domingos do Araguaia (um caso), totalizando dois casos confirmados no Pará.

No ano de 2016, foram confirmados 292 casos de CHIKF no município de Belém, a segunda maior ocorrência no estado, ficando atrás somente de São Domingos do Araguaia, que confirmou 376 casos da doença. Ao todo, no ano de 2016 foram confirmados 1.546 casos de CHIKF no Pará.

Em 2017, o maior número de casos confirmados da doença foi no município de Xinguara, com 1.502 casos. O município de Parauapebas, por sua vez, confirmou 1.466 casos da doença, ficando no segundo lugar do ranking paraense. A capital Belém ficou em terceiro lugar, com 972 casos confirmados. No Pará como um todo, no ano de 2017 foram confirmados 7.309 casos, com o registro de sete óbitos pelo agravo da doença (cinco em Xinguara, um no município de Conceição do Araguaia e um no município de Redenção).

Em 2018, Belém teve o maior número de registros da doença no estado, com 3.032 casos confirmados, o segundo maior registro tendo sido no município de
Marituba, com 1.503 casos confirmados, e em terceiro lugar ficou o município de Ananindeua, que registrou 674 casos.

Em 2018, os três municípios com os maiores números de ocorrência de CHIKF integram a Região Metropolitana de Belém (RMB). $O$ único óbito pelo agravo da doença em 2018 no estado do Pará foi registrado em Belém.

De acordo com o banco de dados disponibilizados pelo Sinan e Sespa, em 2016, 2017 e 2018, foram confirmados respectivamente 292, 972 e 3.032 casos de CHIKF no município de Belém. Em 2016 e 2017 o número de ocorrências de CHIKF aumentou 233\%, e de 2017 a 2018 houve crescimento de $212 \%$ no número de casos da doença na capital paraense.

A Figura 2 apresenta as ocorrências semanais de CHIKF, temperatura, precipitação pluviométrica e ocorrências de CHIKF para os anos de 2016, 2017 e 2018.

Em 2016, observa-se aumento nas ocorrências de CHIKF na 37a semana (mês de setembro) em diante, com pico máximo na 45a semana (mês de novembro), nas quais as ocorrências diminuem gradativamente até o fim da 52 a semana epidemiológica. O baixo número de ocorrências, identificado no primeiro semestre de 2016, provavelmente se deu

Tabela 2 - Estatísticas descritivas semestrais para as ocorrências de febre chikungunya (CHIKF), temperatura do ar e precipitação pluviométrica para os anos de 2016, 2017 e 2018.

\begin{tabular}{|c|c|c|c|c|c|c|c|c|c|c|c|c|c|c|c|}
\hline \multirow[b]{2}{*}{2016} & \multicolumn{5}{|c|}{ CHIKF } & \multicolumn{5}{|c|}{ T. $\operatorname{ar}\left({ }^{\circ} \mathrm{C}\right)$} & \multicolumn{5}{|c|}{ Precipitação (mm) } \\
\hline & Média & DP & $\mathrm{CV}$ & Máx. & Mín. & Média & $\mathrm{DP}$ & $\mathrm{CV}$ & Máx. & Mín. & Média & DP & $\mathrm{CV}$ & Máx. & Mín. \\
\hline 10 & 0,6 & 0,8 & 1,3 & 2,0 & 0,0 & 27,4 & 0,5 & 0,0 & 28,7 & 25,9 & 90,9 & 54,7 & 0,6 & 184,5 & 0,0 \\
\hline 20 & 10,7 & 8,9 & 0,8 & 31,0 & 0,0 & 27,6 & 0,6 & 0,0 & 28,6 & 26,5 & 37,1 & 35,1 & 0,9 & 127,3 & 0,0 \\
\hline 2017 & Média & DP & $\mathrm{CV}$ & Máx. & Mín. & Média & $\mathrm{DP}$ & $\mathrm{CV}$ & Máx. & Mín. & Média & DP & $\mathrm{CV}$ & Máx. & Mín. \\
\hline 10 & 24,2 & 14,0 & 0,6 & 53,0 & 1,0 & 26,7 & 0,6 & 0,0 & 27,8 & 25,7 & 107,9 & 59,1 & 0,5 & 211,3 & 15,2 \\
\hline 20 & 13,2 & 7,8 & 0,6 & 30,0 & 1,0 & 27,5 & 0,5 & 0,0 & 28,5 & 26,2 & 29,2 & 29,6 & 1,0 & 117,2 & 0,0 \\
\hline 2018 & Média & DP & $\mathrm{CV}$ & Máx. & Mín. & Média & $\mathrm{DP}$ & $\mathrm{CV}$ & Máx. & Mín. & Média & DP & $\mathrm{CV}$ & Máx. & Mín. \\
\hline 10 & 77,0 & 37,2 & 0,5 & 146,0 & 13,0 & 26,6 & 0,4 & 0,0 & 27,7 & 26,0 & 186,6 & 3,4 & 0,0 & 193,9 & 181,2 \\
\hline 20 & 39,6 & 35,5 & 0,9 & 87,0 & 0,0 & 27,2 & 0,6 & 0,0 & 28,2 & 25,9 & 190,0 & 4,6 & 0,0 & 197,5 & 180,9 \\
\hline
\end{tabular}

T. ar: grau Celsius (símbolo: ${ }^{\circ} \mathrm{C}$ ); DP: desvio padrão; CV: coeficiente de variação; máx: máximo; mín: mínimo. 


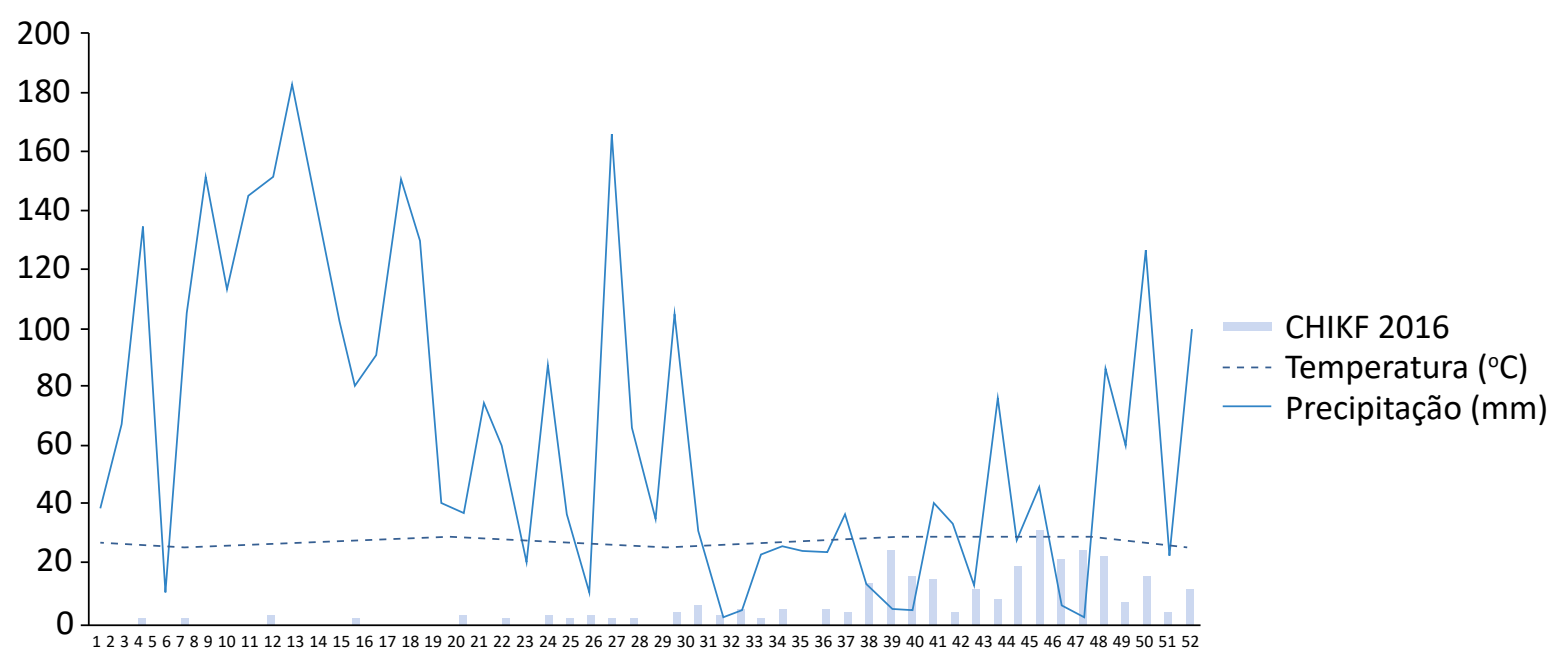

Semana Epidemiológica 2016

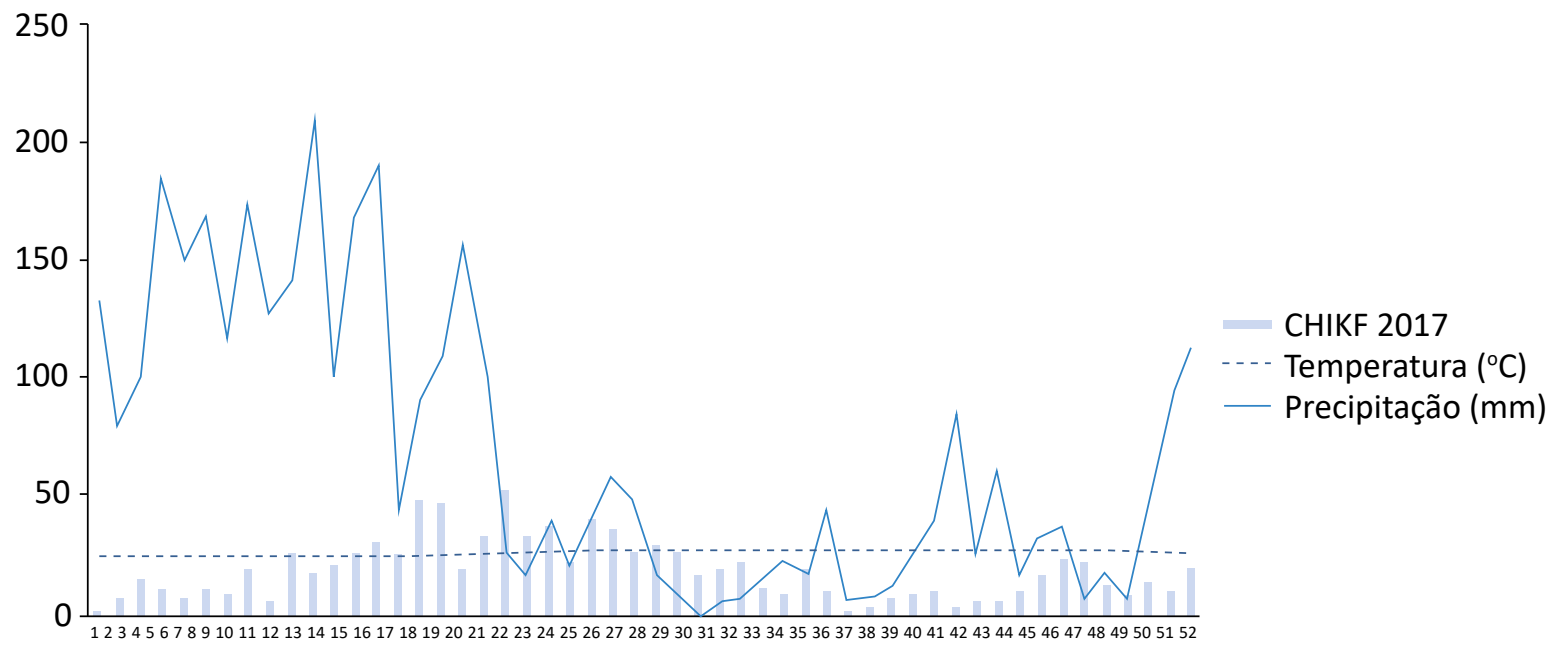

Semana Epidemiológica 2017

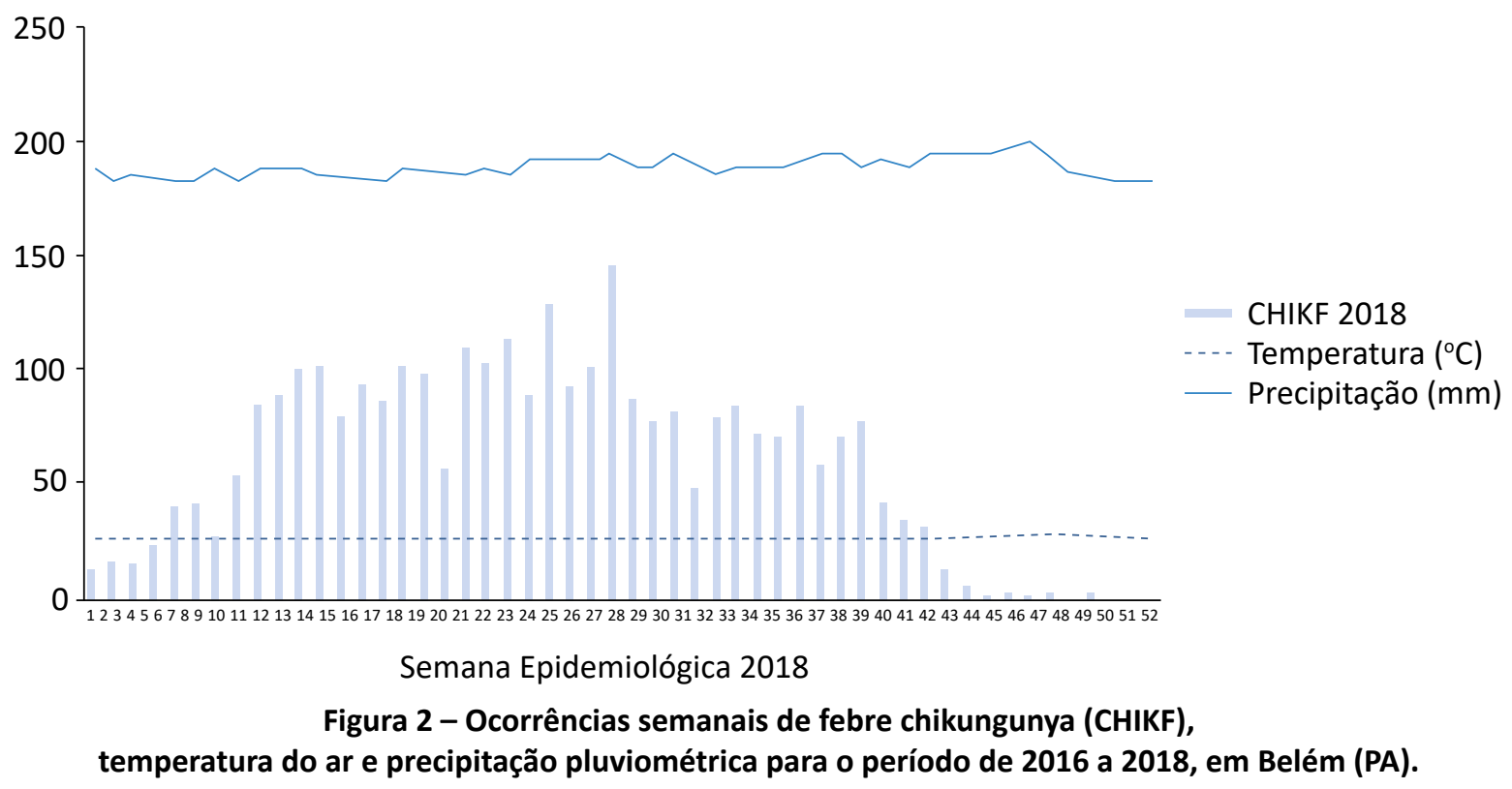


em razão de subnotificações da doença, considerando que em Belém o primeiro caso de CHIKF foi confirmado no fim do segundo semestre de 2015, o que deve ter contribuído para que muitos casos tenham sido notificados como dengue, que é uma arbovirose endêmica no município. No decorrer de 2017, a notificação da doença tem seu pico máximo na 20 ạ semana (mês de maio), que corresponde ao término do período chuvoso da região, passando a apresentar redução gradual. Em 2018, vê-se o pico máximo das notificações da doença na 26a semana epidemiológica (mês de julho), correspondente ao período de estiagem, na qual há redução contínua até a 43a semana epidemiológica (mês de outubro), mantendo praticamente um padrão contínuo até a 52 a semana epidemiológica.

\section{Correlação entre as variáveis climáticas e epidemiológicas}

O gráfico de dispersão apresentado na Figura 3A apresenta relação direta entre os registros de CHIKF e temperatura do ar, ou seja, os registros da CHIKF aumentaram com o aumento da temperatura. Por sua vez, a Figura 3B traz relação inversa, ou seja, há diminuição nas ocorrências da doença no período menos chuvoso, enquanto a Tabela 3 contém o resultado dos testes paramétricos e não paramétricos das variáveis climáticas de temperatura, precipitação e as ocorrências de CHIKF.

O teste de normalidade para as ocorrências de CHIKF em 2016 apresentou $p<0,05$. Definiu-se pela logaritmização da variável dependente para normalizar e homogeneizar sua distribuição, o que possibilitou o uso da correlação linear de Pearson, indentificando correlação positiva e fraca entre as ocorrências de CHIKF e temperatura do ar $(r=0,337 ; p<0,05)$ e correlação negativa e fraca entre as ocorrências de $\mathrm{CHIKF}$ e precipitação pluviométrica $(r=-0,345 ; p<0,05)$. Confirmada a existência de correlação, procedeu-se à regressão linear múltipla, contudo antes de fazer uso do modelo foi feito o teste $\mathrm{F}$ de significância global, que respondeu à seguinte pergunta: "o modelo é útil para prever as ocorrências de febre CHIKF com base nas variáveis de temperatura e precipitação?". O valor do $R^{2}$ ajustado $(0,150)$ indica que as variáveis explicam, aproximadamente, $15 \%$ dos agravos da doença. $A$ análise resultou em um modelo estatisticamente significativo $\left[F(2,32)=2,833 ; p>0,05 ; R^{2}=0,150\right]$, com temperatura do ar $(\beta=0,212 ; t=1,092 ; p>0,05)$ e precipitação pluviométrica $(\beta=0,230 ; t=-1,183$; $p>0,05)$. Isso quer dizer que a temperatura do ar impactou positivamente sobre a CHIKF, ou seja, com o aumento da temperatura há aumento nas ocorrências, enquanto a precipitação pluviométrica impactou negativamente, ou seja, as ocorrências de CHIKF diminuem no período menos chuvoso.

Em 2017, as ocorrências de CHIKF apresentaram distribuição normal $(p>0,05)$. Nesse sentido, procedeu-se à correlação de Pearson, que não identificou associação entre ocorrências de CHIKF, temperatura do $\operatorname{ar}(r=-0,149 ; p>0,05)$ e precipitação pluviométrica $(r=0,37 ; p>0,05)$.
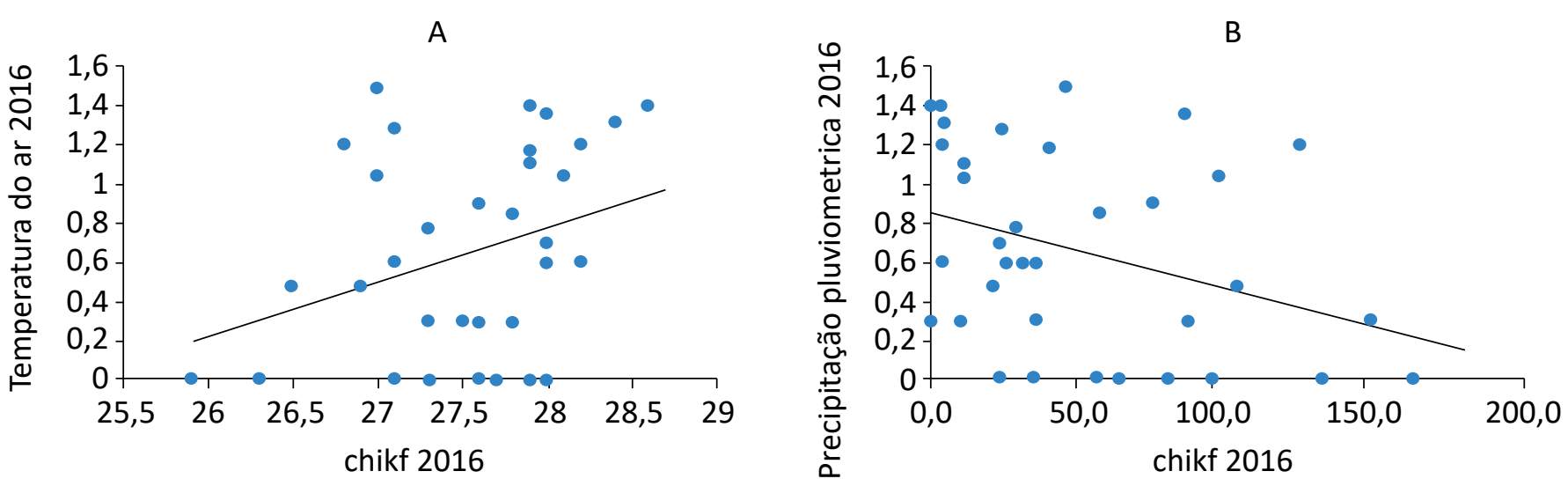

Figura 3 - Dispersão para a precipitação, temperatura e ocorrências de febre chikungunya (CHIKF), para Belém (PA), no ano de 2016. 
Tabela 3 - Testes de correlação entre as ocorrências de febre chikungunya (CHIKF) e as variáveis de temperatura do ar e precipitação pluviométrica, para Belém (PA), de 2016 a 2018.

\begin{tabular}{|c|c|c|c|}
\hline \multicolumn{4}{|c|}{ Matriz de correlação } \\
\hline \multicolumn{4}{|c|}{ Variáveis } \\
\hline & Correlação & Temperatura $\left({ }^{\circ} \mathrm{C}\right)$ & Precipitação (mm) \\
\hline \multirow{2}{*}{2016} & Pearson ${ }^{\circledR}$ & 0,337 & $-0,345^{*}$ \\
\hline & Significância & 0,048 & 0,043 \\
\hline \multirow{2}{*}{2017} & Pearson $^{\circledast}$ & 0,058 & 0,025 \\
\hline & Significância & 0,684 & 0,860 \\
\hline \multirow{2}{*}{2018} & Spearman $^{\circledR}$ & 0,051 & 0,063 \\
\hline & Significância & 0,721 & 0,657 \\
\hline \multicolumn{4}{|c|}{ Legenda } \\
\hline & & Positiva & Negativa \\
\hline Fraca & & 0,01 a 0,39 & $-0,01 a-0,39$ \\
\hline Moderada & & 0,40 a 0,69 & $-0,40 a-0,69$ \\
\hline Forte & & 0,70 a 0,89 & $-0,70 a-0,89$ \\
\hline Perfeita & & 0,90 a 1,00 & $-0,90 a-1,00$ \\
\hline
\end{tabular}

Em 2018, as ocorrências de CHIKF não apresentaram distribuição normal $(p<0,05)$. Desse modo, optou-se pela logaritmização da variável, que ainda assim não apontou padrão de distribuição normal, fazendo-se uso do teste não paramétrico de Spearman, que não identificou correlação entre as ocorrências da doença e a temperatura do $\operatorname{ar}(\rho=0,051 ; p>0,05)$ nem a precipitação pluviométrica $(\rho=-0,063 ; p>0,05)$.

\section{DISCUSSÃO}

No triênio, a distribuição temporal da doença apresentou comportamento sazonal com maiores ocorrências de CHIKF no primeiro semestre de cada ano, que coincide com o período mais chuvoso da região.

Câmara et al. (2009) investigaram os efeitos da temperatura e precipitação associados às epidemias de dengue no Rio de Janeiro (RJ), entre 1986 e 2003. Nesse período ocorreram cinco grandes epidemias nas quais as médias das temperaturas para os primeiros trimestres dos anos de epidemias foram comparadas (teste $t$ ) com as médias dos trimestres correspondentes dos demais anos, as quais se mostraram significativamente mais altas que nos anos não epidêmicos, enquanto não foi encontrada associação entre os casos de dengue e a pluviosidade.
Viana e Ignotti (2013) em estudo de revisão sistemática da literatura de artigos científicos publicados no período de 1991 a 2010 sobre a ocorrência da dengue no Brasil e a sua relação com variáveis meteorológicas concluíram que, mesmo considerando as dificuldades no estabelecimento de um padrão sazonal chave da doença, por causa da diversidade de biomas e diferentes compartimentos climáticos nas distintas regiões geográficas brasileiras, se identifica aumento na ocorrência do agravo da doença principalmente no primeiro semestre de cada ano, período de pluviosidade e temperaturas mais elevadas na maior parte do país.

O estudo de Ferreira et al. (2018), em Araraquara (SP), entre 1991 e 2015, identificou comportamento sazonal 
com aumento do número de casos de dengue nos meses de março a maio, que foram atribuídas às chuvas de janeiro a março, ou seja, chuva em um mês provoca aumento no número de casos nos dois meses subsequentes. Enquanto isso, a relação entre a temperatura e a infestação larvária foi leve e pareceu não ter influência sobre a doença, uma vez que as altas temperaturas, tanto no verão quanto no inverno, são adequadas para a proliferação do vetor.

A sazonalidade também foi identificada por Mahajan e Mahajan (2018), ao constatarem maiores casos de CHIKF no distrito de Amritsar, Punjab (Índia). Ocorreu entre setembro e dezembro, com pico de transmissão da doença em novembro, atribuído à estação quente e chuvosa nos meses de julho a setembro.

A regressão linear apontou associação correlacional fraca e significativa entre as ocorrências de CHIKF e as variáveis de temperatura do ar e de precipitação pluviométrica somente para o ano de 2016. Esses resultados são condizentes com as explicações de Depradine e Lovell (2004), de que o clássico procedimento de correlacionar casos de arboviroses transmitidas por mosquitos vetores com variáveis climáticas é fraco, de maneira geral em razão do efeito time lag, relacionado ao intervalo de tempo (defasagem) entre o fator biológico, a transmissão e o registro dos casos da doença no sistema de informação.

O papel dos fatores climáticos na dinâmica de transmissão das doenças arbovirais transmitidas por mosquito vetor tem sido bastante estudado, sendo a temperatura reconhecidamente o fator abiótico que mais exerce influência direta e indireta sobre o vetor, o vírus e suas interações (RAMADONA et al., 2016; OGDEN, 2017; BENÍTEZ et al., 2019). A elevação da temperatura reduz o tempo de desenvolvimento das larvas, o que contribui para o aumento da população de mosquitos adultos, acelerando a taxa de metabolismo do mosquito e a capacidade de digestão sanguínea, o que faz com que o vetor se alimente com maior frequência, aumentando, consequentemente, a intensidade da transmissão (GITHEKO et al., 2000; RAMADONA et al., 2016; BENÍTEZ et al., 2019). Sobre o vírus, o aumento da temperatura exerce influência na replicação e maturação do vírus no vetor, contribuindo com a diminuição do período de incubação extrínseca, possibilitando, assim, maiores proporções de mosquitos infecciosos (CÂMARA et al., 2009; CORRÊA et al., 2016; BENÍTEZ et al., 2019).
Entretanto, destaca-se que os mosquitos do gênero Aedes funcionam em uma faixa de temperatura ótima, além dos pontos mínimos e máximos críticos para os quais sua atividade é impossível e o risco de morte aumenta. Mesmo com variações, tem sido demonstrado que esse vetor se desenvolve plenamente entre $15 \mathrm{e}$ 35으 (REINHOLD et al., 2018).

Já o efeito da precipitação pluviométrica se relaciona com as condições sociais e ambientais locais, uma vez que a chuva aumenta a disponibilidade de hábitat larval, bem como permite que os ovos dos Aedes se transformem em mosquitos adultos, aumentando a densidade populacional do vetor. Entretanto, essa relação nem sempre é linear, uma vez que fortes chuvas podem destruir os criadouros existentes de mosquitos, afetar a maturação de ovos ou larvas e, consequentemente, influenciar desfavoravelmente a abundância do vetor (VIANA; IGNOTTI, 2013; LIMA et al., 2016; RAMADONA et al., 2016; Ll et al., 2017; LOWE et al., 2018).

Com o objetivo de compreender os efeitos de defasagem entre variáveis climáticas e ocorrências de dengue, Ribeiro et al. (2006), utilizando a correlação não paramétrica de Spearman, não observaram associação entre os valores de temperatura e pluviosidade e o número de casos da doença quando as variáveis foram associadas para o mesmo mês de análise. Tal associação passou a ser observada quando os valores dos fatores abióticos de determinado mês foram ligados ao número de casos da doença do mês seguinte. Essa defasagem revelou associação significativa no segundo, no terceiro e no quarto mês de observação. Ou seja, a chuva e a temperatura de determinado mês contribuíram para explicar o número de casos de dengue de dois até quatro meses depois, quando as respectivas forças de associação se estabilizaram.

Ramadona et al. (2016) utilizaram séries temporais de dados meteorológicos e de dengue para desenvolver um modelo de alerta precoce para surtos da doença na província de Yogyakarta, na Indonésia. Após testes de normalidade e autocorrelação, foram utilizados modelos de regressão não lineares que identificaram que a temperatura com defasagem de três meses e a precipitação com defasagem de dois ou três meses foram melhores preditores para o modelo.

Li et al. (2017) propuseram um modelo de alerta precoce para surtos de dengue na província de Guangdong 
(China), integrando dados de consulta na internet, dados de vigilância epidemiológica e dados meteorológicos de temperatura e precipitação. Por meio de associações não lineares, os resultados identificaram que a defasagem se correlacionava positivamente com a temperatura mínima semanal média em um intervalo de nove semanas, enquanto a precipitação influenciava na abundância de vetores nas semanas subsequentes.
Lowe et al. (2018), mediante o conceito de defasagem, elaboraram um modelo de previsão para surtos de dengue tendo em vista eventos climáticos extremos. Os resultados encontrados sugerem que as condições de seca influenciam positivamente nas ocorrências de dengue em prazos de até cinco meses, enquanto o excesso de chuvas aumenta o risco em prazos mais curtos, entre um e dois meses.

\section{CONCLUSÃO}

A análise temporal constatou o aumento no número de casos da doença entre 2016 e 2018 . No período analisado, houve padrão sazonal com maiores ocorrências da CHIKF no primeiro semestre, no qual foram registrados maiores índices de chuvas e temperaturas mais amenas, e houve redução no número de registros da doença no segundo semestre, que coincide com o período de estiagem da região.

Em 2016, a temperatura do ar correlacionou-se positivamente com a CHIKF, enquanto precipitação pluviométrica se correlacionou negativamente com a doença.
A regressão linear múltipla identificou correlação positiva e fraca entre a temperatura do ar e a CHIKF e correlação negativa e fraca entre a precipitação pluviométrica e a CHIKF em 2016. Esses resultados reforçam a necessidade de considerar o efeito time lag no estudo das arboviroses transmitidas por mosquito vetor.

Convém ainda destacar que as arboviroses, como a febre CHIKF, apresentam causas multifatoriais, como, por exemplo, relação com a infraestrutura urbana precária e com as condições socioeconômicas, como a densidade populacional, a renda, entre outras.

\section{AGRADECIMENTOS}

Agradecimento à Coordenação de Aperfeiçoamento de Pessoal de Nível Superior (CAPES), a concessão de bolsa de pesquisa.

\section{REFERÊNCIAS}

ALMEIDA, C.A.P.; SILVA, R.M. Modelagem espacial dos casos de dengue e variáveis socioambientais em João Pessoa, Cabedelo e Bayeux, Paraíba. Revista Brasileira de Geografia Física, v. 10, n. 5, 2017. https://doi.org/10.26848/rbgf.v10.n5.p1455-1470

AZEVEDO, T.S. de; PIOVEZAN, R.; ZUBEN, C.J.V.; ANDRÉ, I.R.N.; ALMEIDA, D. Perfil epidemiológico da dengue no município de Rio Claro no período de 1996 a 2010. Revista Brasileira de Geografia Médica e da Saúde - Hygeia, v. 7, n. 12, p. 19-30, jun. 2011.

BASTOS, T.X.; PACHECO, N.A.; NECHET, D.; SÁ, T.D. de A. Aspectos climáticos de Belém nos últimos cem anos. Belém: Embrapa Amazônia Oriental, 2002. 31 p.

BENÍTEZ, Y.M.; CORTÉS, K.J.M.; MONTENEGRO, E.G.M.; GARCÍA, V.H.P.; DÍAZ, A.L.M. Influencia de la temperatura ambiental en el mosquito Aedes spp. y la transmisión del virus del dengue. CES Medicina, v. 33, n. 1, p. 43, 2019. http://dx.doi.org/10.21615/cesmedicina.33.1.5

CÂMARA, F.P.; GOMES, A.F.; SANTOS, G.T.; CÂMARA, D.C.P. Clima e epidemias de dengue no Estado do Rio de Janeiro. Revista da Sociedade Brasileira de Medicina Tropical, v. 42, n. 2, p. 137-140, mar.-abr. 2009. http://dx.doi.org/10.1590/S0037-86822009000200008 
CORRÊA, J.A.J.; COSTA, A.C.L.; PEREIRA, I.C.N. Associação entre a precipitação pluviométrica e a incidência de dengue em sete municípios do estado do Pará. Revista Brasileira de Geografia Física, v. 9, n. 7, p. 2264-2276, 2016. http://dx.doi.org/10.5935/1984-2295.20160161

COSTA, C.E.A.S.; BLANCO, C.J.C. Influência da variabilidade climática sobre a erosividade em Belém (PA). Revista Brasileira de Meteorologia, v. 33, n. 3, p. 509-520, 2018. http://dx.doi.org/10.1590/0102-7786333010

COSTA, S.D.S.B.; BRANCO, M.D.R.F.C.; AQUINO JUNIOR, J.; RODRIGUES, Z.M.R.; QUEIROZ, R.C.S.; ARAÚJO, A.S.; CÂMARA, A.P.B.; SANTOS, P.S.; PEREIRA, E.D.A.; SILVA, M.S.; COSTA, F.R.V.; SANTOS, A.V.D.; MEDEIROS, M.N.L.; ALCÂNTARA JÚNIOR, J.O.; VASCONCELOS, V.V.; SANTOS, A.M.; SILVA, A.A.M. Spatial analysis of probable cases of dengue fever, chikungunya fever and zika virus infections in Maranhao State, Brazil. Revista do Instituto de Medicina Tropical de São Paulo, v. 60, 2018. http://dx.doi.org/10.1590/S1678-9946201860062

COSTA,Z.G.A.; ROMANO, A.P.M.;ELKHOURY,A.N.M.;FLANNERY, B. Evolução histórica da vigilância epidemiológica e do controle da febre amarela no Brasil. Revista Pan-Amazônica de Saúde, v. 2, n. 1, p. 11-26, 2011. http://dx.doi.org/10.5123/S2176-62232011000100002

DEPRADINE, C.A.; LOVELL, E.H. Climatological variables and the incidence of dengue fever in Barbados. International Journal of Environmental Health Research, v. 14, n. 6, p. 429-441, 2004. http://dx.doi.org/10.1080/09603120400012868

DONALISIO, M.R.; FREITAS, A.R. Chikungunya in Brazil: an emerging challenge. Revista Brasileira de Epidemiologia, v. 18, n. 1, p. 283-285, 2015. http://dx.doi.org/10.1590/1980-5497201500010022

FENZL, N.; MENDES, R.L.; RODRIGUES, L.L.F. A sustentabilidade do sistema de abastecimento de água: da captação ao consumo de água em Belém. Belém: NUMA/UFPA, 2010. 140 p.

FERREIRA, A.C.; CHIARAVALLOTI NETO, F.; MONDINI, A. Dengue em Araraquara, SP: epidemiologia, clima e infestação por Aedes aegypti. Revista de Saúde Pública, v. 52, n. 18, 2018. https://dx.doi.org/10.11606/s1518-8787.2018052000414

FRANCO, V.S.; SOUZA, E.B. de; COSTA, C.P.W. da; FERREIRA, D.B.S.; OLIVEIRA, J.V. de; SODRÉ, G.R.C.; KUHN, P.A.F.; AZEVEDO, F.T.M de. Prognóstico sazonal da precipitação pluviométrica para o verão e outono austral da Amazônia oriental. Revista Brasileira de Geografia Física, v. 12, n. 1, p. 57-70, 2019. https://dx.doi.org/10.26848/rbgf.v12.1.p057-070

FUNDAÇÃO OSWALDO CRUZ (FIOCRUZ). Dengue: Vírus e Vetor. Fiocruz. Disponível em: <http://www.ioc.fiocruz.br/ dengue/textos/longatraje.html>. Acesso em: 20 set. 2019.

GITHEKO, A.K.; LINDSAY, S.W.; CONFALONIERI, U.E.; PATZ, J.A. Climate change and vector-borne diseases: a regional analysis. Bulletin of the World Health Organization, v. 78, n. 9, p. 1136-1147, 2000.

GOULD, E.A.; GALLIAN, P.; LAMBALLERIE, X. de; CHARREL, R.N. First cases of autochthonous dengue fever and chikungunya fever in France: from bad dream to reality. Clinical Microbiology and Infection, v. 16, n. 12, p. 1702-1704, 2010. https://dx.doi.org/10.1111/j.1469-0691.2010.03386.x

HALSTEAD, S.B. Reappearance of Chikungunya, Formerly Called Dengue, in the Americas. Emerging Infectious Diseases, v. 21, n. 4, 2015. https://dx.doi.org/10.3201/eid2104.141723

HONÓRIO, N.A.; CÂMARA, D.C.P.; CALVET, G.A.; BRASIL, P. Chikungunya: uma arbovirose em estabelecimento e expansão no Brasil. Cadernos de Saúde Pública, Rio de Janeiro, v. 31, n. 5, p. 906-908, 2015. https://dx.doi.org/10.1590/0102-311XPE020515

HUMPHREY, J.M.; CLETON, N.B.; REUSKEN, C.B.E.M.; GLESBY, M.J.; KOOPMANS, M.P.G.; ABU-RADDAD, L.J. Urban Chikungunya in the Middle East and North Africa: A systematic review. PLOS Neglected Tropical Diseases, v. 11, n. 6, p. e0005707, 2017. https://doi.org/10.1371/journal.pntd.0005707

INSTITUTO BRASILEIRO DE GEOGRAFIA E ESTATÍsTICA (IBGE). Censo demográfico. Rio de Janeiro: IBGE, 2010. Disponível em: <http://www.ibge.gov.br/estadosat/l>. Acesso em: 21 mar. 2017. 
JANSEN, C.C.; WILLIAMS, C.R.; VAN DEN HURK, A.F. The Usual Suspects: Comparison of the Relative Roles of Potential Urban Chikungunya Virus Vectors in Australia. PLoS One, v. 10, n. 8, 2015. http://doi.org/10.1371/journal.pone.0134975

LI, Z.; LIU, T, ZHU, G.; LIN, H.; ZHANG, Y.; HE, J.; DENG, A.; PENG, Z.; XIAO, J.; RUTHERFORD, S.; XIE, R.; ZENG, W.; LI, X.; MA, W. Dengue Baidu Search Index data can improve the prediction of local dengue epidemic: A case study in Guangzhou, China. PLoS Neglected Tropical Disease, v. 11, n. 3, 2017. http://doi.org/10.1371/journal.pntd.0005354

LIMA, R.C.; MOREIRA, E.B.M.; NÓBREGA, R.S. A influência climática sobre a epidemia de dengue na cidade do Recife por Sistemas de Informações Geográficas. Revista Brasileira de Geografia Física, v. 9, n. 2, p. 384-398, 2016. https://doi.org/10.26848/rbgf.v9.2.p384-398

LOWE, R.; GASPARRINI, A.; VAN MEERBEECK, C.J.; LIPPI, C.A.; MAHON, R.; TROTMAN, A.R.; ROLLOCK, L.; HINDS, A.Q.J.; RYAN, S.J.; STEWART-IBARRA, A. Nonlinear and delayed impacts of climate on dengue risk in Barbados: A modelling study. PLoS Medicine, v. 15, n. 7, 2018. https://doi.org/10.1371/journal.pmed.1002613

MAHAJAN, S.L.; MAHAJAN, K. Epidemiological Profile of Chikungunya Cases Reported in Year 2016 in District Amritsar, Punjab (India). Archives of Epidemiology, 2018.

MOREIRA, F.S.A.; FERREIRA, G.R.B.; DIAS, L.C.; VITORINO, M.I. Variabilidade da precipitação na Cidade de Belém-PA e sua relação com a incidência de leptospirose. Revista Brasileira de Geografia Física, v. 12, n. 1, p. 71-80. 2019. https://doi.org/10.26848/rbgf.v12.1.p071-080

NAVECA, F.G.; CLARO, I.; GIOVANETTI, M.; DE JESUS, J.G.; XAVIER, J.; IANI, F.C.D.M.; NACIMENTO, V.A.;SOUZA, V.C.; SILVEIRA, P.P.; LOURENÇO, J.; SANTILLANA, M.; KRAEMER, M.U.G.; QUICK, J.; HILL, S.C.; THÉZÉ, J.; CARVALHO, R.D.O.; AZEVEDO, V.; SALLES, F.C.S.; NUNES, M.R.T.; LEMOS, P.S.; CANDIDO, D.S.; PEREIRA, G.C.; OLIVEIRA, M.A.A.; MENESES, C.A.R.; MAITO, R.M.; CUNHA, C.R.S.B.; CAMPOS, D.P.S.; CASTILHO, M.C.; SIQUEIRA, T.C.S.; TERRA, T.M.; ALBUQUERQUE, C.F.C.; CRUZ, L.N.; ABREU, A.L.; MARTINS, D.V.; SIMÕES, D.S.M.V.; AGUIAR, R.S.; LUZ, S.L.B.; LOMEN, N.; PYBUS, O.G.; SABINO, E.C.; OKUMOTO, O.; ALCÂNTARA, L.C.J.; FARIA, N.R. Genomic, epidemiological and digital surveillance of Chikungunya virus in the Brazilian Amazon. PLoS Neglected Tropical Disease, v. 13, n. 3, 2019. https://doi.org/10.1371/journal.pntd.0007065

OGDEN, N.H. Climate change and vector-borne diseases of public health significance. FEMS Microbiology Letters, v. 364, n. 19, 2017. https://doi.org/10.1093/femsle/fnx186

PANDEY, B.D.; NEUPANE, B.; PANDEY, K.; TUN, M.M.; MORITA, K. Detection of Chikungunya Virus in Nepal. American Journal of Tropical Medicine Hygiene, v. 93, n. 4, p. 697-700, 2015. https://doi.org/10.4269/ajtmh.15-0092

PATTERSON, J.; SAMMON, M.; GARG, M. Dengue, Zika and Chikungunya: Emerging Arboviruses in the New World. Western Journal of Emergency Medicine, v. 17, n. 6, p. 671-679, 2016. https://doi.org/10.5811/westjem.2016.9.30904

RAMADONA, A.L.; LAZUARDI, I.L.; HII, Y.L.; HOLMNER, A.; KUSNANTO, H.; ROCKLÖV, J. Prediction of Dengue Outbreaks Based on Disease Surveillance and Meteorological, Data. PLoS One, v. 11, n. 3, 2016. https://doi.org/10.1371/journal.pone.0152688

REINHOLD, J.M.; LAZZARI, C.R.; LAHONDÈRE, C. Effects of the Environmental Temperature on Aedes aegypti and Aedes albopictus Mosquitoes: A Review. Insects, v. 9, n. 4, p. 158, 2018. https://doi.org/10.3390/insects9040158

RIBEIRO, A.F.; MARQUES, G.R.A.; VOLTOLINI, J.C.; CONDINO, M.L.F. Associação entre incidência de dengue e variáveis climáticas. Revista Saúde Pública, v. 40, n. 4, p. 671-676, 2006. http://dx.doi.org/10.1590/S0034-89102006000500017

RODRIGUES, E.A.S.; COSTA, I.M.; LIMA, S.C. Epidemiologia da dengue, zika e chikungunya, entre 2014 a 2016, em Uberlândia (MG). Hygeia, v. 14, n. 30, p. 62-81, 2018.

RODRIGUES, N.C.P.; DAUMAS, R.P.; ALMEIDA, A.S.; SANTOS, R.S.; KOSTER, I.; RODRIGUES, P.P.; GOMES, M.F.; MACEDO, A.F.; GERARDI, A.; LEITE, I.C. Risk factors for arbovirus infections in a low-income community of Rio de Janeiro, Brazil, 2015-2016. PLoS One, v. 13, n. 6, 2018. https://doi.org/10.1371/journal.pone.0198357 
SAM, I.C.; KÜMMERER, B.M.; CHAN, Y.F.; ROQUES, P.; DROSTEN, C.; ABUBAKAR, S. Updates on chikungunya epidemiology, clinical disease, and diagnostics. Vector-Borne and Zoonotic Diseases, v. 15, n. 4, p. 223-230, 2015. https://doi.org/10.1089/vbz.2014.1680

SILVA, N.M.; TEIXEIRA, R.A.G.; CARDOSO, C.G.; SIQUEIRA JÚNIOR, J.B.; COELHO, G.E.; OLIVEIRA, E.S.F. Vigilância de chikungunya no Brasil: desafios no contexto da Saúde Pública. Epidemiologia Serviços de Saúde, Brasília, v. 27, n. 3, p. e2017127, 2018b. http://dx.doi.org/10.5123/s1679-49742018000300003

SILVA, T.C.C.; SANTOS, A.P.B.; MUSSALEM, T.M.;VALADARES-KOSKI, A.P.; NADER, P.R.A. Aspectos epidemiológicos da Chikungunya no Estado do Espírito Santo, Brasil, 2014 a 2017. Revista Guará, v. 6, n. 9, 21-30, 2018 a. https://doi.org/10.30712/guara.v6i9.19492

TAURO, L.B.; CARDOSO, C.W.; SOUZA, R.L.; NASCIMENTO, L.C.J.; SANTOS, D.R.; CAMPOS, G.S.; SARDI, S.; REIS, O.B.; REIS, O.B.; REIS, M.G.; KITRON, U.; RIBEIRO, G.S. A localized outbreak of Chikungunya virus in Salvador, Bahia, Brazil. Memórias do Instituto Oswaldo Cruz, v. 114, p. 124-132, 2019. http://dx.doi.org/10.1590/0074-02760180597

VIANA, D.V.; IGNOTTI, E. A ocorrência da dengue e variações meteorológicas no Brasil: revisão sistemática. Revista Brasileira de Epidemiologia, v. 16, n. 2, p. 240-256, 2013. http://dx.doi.org/10.1590/S1415-790X2013000200002

WIMALASIRI-YAPA, B.M.C.; STASSEN, L.; HUANG, X.; HAFNER, L.M.; HU, W.; DEVINE, G.J.; YAKOB, L.; JANSEN, C.C.; FADDY, H.M.; VIENNET, E.; FRENTIU, F.D. Chikungunya virus in Asia - Pacific: a systematic review. Emerging Microbes \& Infections, v. 8, n. 1, p. 70-79, 2019. https://dx.doi.org/10.1080\%2F22221751.2018.1559708 